\title{
Crisis política y cine nacional. Aproximaciones entre cine, política y patrimonialización en Uruguay (1965-1967) ${ }^{1}$
}

\author{
Political crisis and national cinema. \\ Approaches between cinema, politics and patrimonialization in \\ Uruguay (1965-1967)
}

Isabel Wschebor Pellegrino

Universidad de la República

Uruguay

DOI: https://doi.org/10.25032/crh.v7i12.10

Recibido: $30 / 3 / 2021$

Aceptado: $23 / 5 / 2021$

Resumen. En el siguiente artículo, me propongo analizar tres escenarios entre 1965 y 1967, donde se expresa un interés específico por la cuestión del cine nacional en Uruguay, como tema de debate en la agenda pública, en el contexto de crisis social y política que comenzó a hacerse evidente en el país en estas mismas fechas. Diversos estudios han señalado el aumento de la producción cinematográfica desde mediados de la década de 1960 en el país y la ampliación de sus formas de circulación a nivel local y regional, a través de festivales y muestras retrospectivas, pese a la inexistencia de una industria propiamente dicha. Se busca comprender el fenómeno cinematográfico, a partir de muy diversos elementos que rodean las obras cinematográficas propiamente dichas y que no están necesariamente asociados a su argumento, contenido o género e identificar de este modo, las diferentes etapas del proceso de patrimonialización del cine en el escenario local.

Palabras clave: Cine, Uruguay, patrimonialización, política

\footnotetext{
${ }^{1}$ Doctoranda en co-tutela entre l'École National des Chartes (París, Centre de Recherche Jean Mabillon) y la Facultad de Humanidades y Ciencias de la Educación de la Udelar. Coordinadora del Laboratorio de Preservación Audiovisual del Archivo General de la Udelar y miembro del Grupo de Estudios Audiovisuales (EI, CSIC, Universidad de la República).
} 
Abstract. In the following article, I propose to analyze three scenarios between 1965 and 1967, where a specific interest is expressed in the "question of national cinema" in Uruguay, as a topic of debate on the public agenda, in the context of social and political crisis that began to become evident in the country at the same time. Various studies have pointed out the increase in film production since the mid-1960s in the country and the expansion of its forms of circulation at the local and regional level, through festivals and retrospective shows, despite the lack of an industry itself. I propose to understand the cinematographic phenomenon, based on very diverse elements that "surround" the cinematographic works themselves and that are not necessarily associated with their content or genre, and thus identify the different stages of the film heritage process in Uruguay.

Keywords: Cinema, Uruguay, Patrimonialisation, Politic

\section{Introducción}

El siguiente artículo constituye un avance de mi tesis doctoral sobre los procesos de patrimonialización del cine en Uruguay durante la segunda mitad del siglo Xx. En la actualidad - guiados por una mirada intuitiva- parecería natural identificar el cine como un patrimonio cultural desde el punto de vista local o transnacional. Sin embargo, su consideración como un bien que ha de ser conservado para el conocimiento de generaciones futuras, constituye una idea relativamente nueva. En general, el cine se ha producido para muy distintas finalidades artísticas, comerciales, políticas, culturales, educativas, por poner solo algunos ejemplos. Desde el punto de vista comercial, las reglamentaciones a las que ha estado sometido incluyen la destrucción de los films tras la caducidad de sus contratos de explotación y exhibición. Para el caso de los productos realizados con fines de difusión a nivel educativo o a través de los medios de comunicación, no siempre han existido reglamentaciones o disposiciones que prevean su permanencia en el tiempo. En ese contexto, las ideas o prácticas sociales e institucionales que han puesto en evidencia el tema de la producción cinematográfica en el ámbito local y la necesidad de preservar el cine en sus diferentes manifestaciones, cuentan con una historia específica. 
A continuación, me propongo analizar tres escenarios entre 1965 y 1967, donde se expresa un interés específico por la cuestión del cine nacional en Uruguay, como tema de debate en la agenda pública. Diversos estudios han señalado el aumento de la producción cinematográfica en el país desde mediados de la década de 1960, la diversificación de los géneros cinematográficos existentes y la ampliación de sus formas de circulación a nivel local y regional, a través de festivales y muestras retrospectivas, pese a la inexistencia de una industria propiamente dicha (Lacruz, 2015, 2016 y 2018 y Tadeo Fuica, 2017). El interés por la cuestión del cine nacional a mediados de la década de 1960, así como el debate en torno a qué significaba producir, exhibir o conservar cine en el país, los diagnósticos sobre su situación en aquel contexto o sus perspectivas de futuro, inscriben estas polémicas en los procesos de patrimonialización del medio, desde la segunda mitad del siglo Xx.

La década de 1960 se caracterizó por un contexto de advenimiento de una crisis aguda desde los puntos de vista político y social a nivel local, tras la imposibilidad de dar soluciones a la crisis económica que se había iniciado en la década anterior. Estos escenarios de debate, se produjeron a su vez en un contexto más amplio de confrontación sobre el posible papel del cine como instrumento expansivo de ciertas ideas de cambio social y político o como promotor de prácticas de desarrollo industrial. Se busca en este sentido, comprender el fenómeno cinematográfico a partir de muy diversos elementos que rodean las obras propiamente dichas y que no están necesariamente asociados a su argumento, contenido o género.

Según el historiador Christophe Gauthier, el devenir del cine como un patrimonio cultural común está asociado a muy diversos factores y prácticas de legitimación, desarrollados de forma paulatina desde fines del siglo XIX en Europa (Gauthier, 2018). Su construcción ha respondido a diversos factores de carácter común y diverso. Christophe Gauthier ha analizado el caso francés, brindando ciertas pautas generales para el abordaje de este proceso, que presentan particularidades para el caso uruguayo. Si bien este autor se centra en el análisis de un país pionero en la producción cinematográfica, algunos de los aspectos analizados parecen ser funcionales al caso uruguayo. Como veremos, otros se presentan de manera específica y se vinculan con el contexto local de la segunda mitad del 
siglo XX.

Según Gauthier, las primeras modalidades de valoración del cine estuvieron asociadas al incremento en la producción de patentes y documentos científicos que registraran su invención como innovación tecnológica y del conocimiento entre fines del siglo XIX y las primeras décadas del XX. En segundo lugar, este autor identifica un segundo jalón de este proceso con la conformación de comunidades cinéfilas que impulsaron la artificación del cine. Es decir, su reconocimiento en el campo de las artes. Las comunidades cinéfilas, organizadas en cine-clubes entre las décadas de 1910 y 1930 en Francia, acompañadas por el desarrollo de una crítica especializada sobre cine en aquel país, se ocuparon de identificar un panteón cinematográfico, que diera al cine un estatuto de séptimo arte. Estas mismas sociedades, influyeron también en la expansión del cine como medio en el ámbito cultural y educativo. El surgimiento de las cinematecas en las primeras décadas del siglo pasado estuvo asociado a estos intereses por parte de la comunidad cinéfila y constituyeron las primeras organizaciones abocadas de forma específica a la conservación cinematográfica y su exhibición, fuera de los circuitos y las lógicas del comercio y la industria (Gauthier, 2018). Su carácter asociativo tuvo como principal expresión a nivel internacional la formación de la Federación Internacional de Archivos Fílmicos (FIAF) a fines de la década de 1930, con especial impulso tras el fin de la Segunda Guerra Mundial. En tercer lugar, Gauthier señala la producción de una historiografía sobre el cine desde la década de 1940, como otro de los factores que permiten explicar su proceso de patrimonialización. En este sentido, contrapone las primeras «memorias culturales» del cine, elaboradas principalmente por integrantes de las generaciones cinéfilas, de una historiografía profesional producida en el período más reciente (Gauthier, 2007). Para finalizar, Gauthier se refiere a algunos elementos de carácter más reciente, como el ingreso de la cinematografía patrimonial en los circuitos de festivales de cine restaurado o de archivo, así como la profesionalización de las comunidades asociadas a la preservación de este tipo de bienes culturales (Gauthier, 2018).

Para el análisis del caso uruguayo, es posible establecer tres tipos de diferencias en relación con lo señalado por Gauthier para el caso francés. En primer lugar, el período 
embrionario caracterizado por la valoración del cine como invento científico tecnológico, no coincide con la recepción de este medio en el caso uruguayo, tras su invención y desarrollo en Europa. En segundo lugar, la conformación de una comunidad cinéfila en Uruguay, el desarrollo de una crítica cinematográfica, así como la configuración de las primeras cinematecas en el ámbito público y privado se produce en las décadas de 1940 y 1950 y estuvo asociada fundamentalmente a la divulgación del cine internacional, ajeno al circuito comercial. Durante la década de 1950, este movimiento estuvo acompañado del impulso de una producción cinematográfica de carácter amateur, pese a la inexistencia de una industria de cine en el país, donde se conformaron las primeras redes de interés por el cine local. Desde el punto de vista de la preservación, la preponderancia de un interés por el cine internacional, la ausencia de una industria y la producción incipiente de cine amateur de circulación restringida estimularon el impulso hacia la conformación de una cultura cinematográfica desde mediados del siglo pasado, inserta en los circuitos internacionales de la FIAF y motivada por la divulgación y el reconocimiento del cine de autor extranjero, en los circuitos de exhibición no comercial locales. Estas acciones se desarrollaron principalmente desde Cine Arte del SODRE a nivel público y desde las redes de cineclubes en el ámbito privado desde fines de la década de 1940. A comienzos de la década de 1950, se fundó la Cinemateca Uruguaya en el ámbito asociativo bajo el impulso de Cine Universitario y Cine Club del Uruguay (Amieva, 2017, Silvera, 2019, Tadeo Fuica, 2020).

Por último, las circunstancias históricas en las que se produce un incremento de la producción cinematográfica en Uruguay desde mediados de la década de 1960, puso en evidencia debates de carácter político-ideológico, asociados al contexto de crisis por el que atravesaba el país (Lacruz, 2016 y 2018). Como veremos, se trata de un período en el que, más que la elaboración de un canon cinematográfico, se configuró un campo independiente en el escenario cultural local, con posiciones diversas en relación con cuál debía ser el devenir del cine producido localmente. El año 1965 ha sido señalado como un momento de cambios en la historia del cine en Uruguay. Los estudios se han focalizado en el aumento de la producción de películas nacionales y su circulación en festivales a nivel local y regional. Dicho movimiento fue el embrión del desarrollo de un cine político y militante, orientado por corrientes del Nuevo Cine Latinoamericano afines a las ideas 
de un cambio social y radical en América Latina (Lacruz, 2016 y 2018). En este sentido, podemos observar en el ámbito local el desarrollo de nuevas posiciones en el campo cinematográfico, que se opusieron a las miradas clásicas de las comunidades cinéfilas organizadas desde las décadas anteriores, orientadas a la difusión y expansión del cine europeo y norteamericano de escasa circulación comercial en el país. Las diferentes posiciones sobre exhibición, producción y conservación del cine a nivel nacional de mediados de la década de 1960 se constituyen de este modo como un jalón en su paulatino proceso de patrimonialización.

Esta investigación dialoga con estudios históricos recientes de la región, asociados a la historia de los archivos de cine y de las cinematecas en la región del Cono Sur. Se trata de investigaciones que han analizado el rol social, cultural y de preservación de estas instituciones a lo largo del siglo xx. Señalamos especialmente los trabajos de Fabián Nuñez sobre la historia de las cinematecas en América Latina y, en particular, de la Unión de Cinematecas Latinoamericanas (UCAL) desde mediados de la década de 1960 (Núñez, 2015, 2017 y 2020) y la reciente publicación de la tesis doctoral de Eugenia Izquierdo sobre la historia de los archivos de cine en Argentina, desde la década de 1940 hasta el inicio del siglo XXI (Izquierdo, 2021).

En primer lugar, analizaremos el conflicto que se desencadena desde enero de 1965, asociado al boicot de la empresa internacional Motion Pictures, para la distribución de estrenos norteamericanos en Uruguay. En segundo lugar, el ingreso de la televisión y las nuevas formas y prácticas de producción que acompañaron el desarrollo de dicho medio de comunicación a nivel local, no solo tuvieron su impacto en las formas de consumo de las películas y sus medios de circulación. También pusieron de manifiesto diversas posturas en torno a la profesionalización de la actividad en el ámbito de la producción audiovisual expresadas por diversos críticos especializados. Por último, entre 1965 y 1967 también se produjeron diversos cambios en las instituciones abocadas a la conservación del cine en el país, donde nuevamente diferentes posiciones en torno al tema se expresaron tanto a nivel público, como en el diálogo entre los diversos actores y las autoridades. Así, la idea misma de cuál debía ser el cine a conservar, para volver a mostrar en el futuro, configuró un tercer escenario de debate en la agenda pública. 


\section{La crisis llega a las salas de cine}

El 28 de diciembre de 1964 el Parlamento Nacional aprobó la Ley 13.319 de recursos para el presupuesto nacional y en su artículo 32, establecía que los contratos de arrendamiento entre distribuidores y exhibidores de películas cinematográficas se realizaría a partir del porcentaje de la venta de entradas y se estimaría sobre el $80 \%$ de lo recaudado. ${ }^{2}$ Dicho artículo refrendaba con fuerza de ley, algunas disposiciones y acuerdos previos de la industria cinematográfica, en cuya negociación habían participado trabajadores, exhibidores y distribuidores, orientados a proteger este sector, tras la franca caída de espectadores en las salas desde fines de la década de 1950, presuntamente asociada a la llegada de la televisión a los hogares en el país. 3 En ese marco, la Ley 13.032 de recursos presupuestales del 7 de diciembre de 1961 establecía la exoneración de impuestos nacionales a los espectáculos cinematográficos y, debido a la falta de precisión en relación con cuáles eran los sectores de dicha industria que serían beneficiarios de la exoneración, ciertas disposiciones y acuerdos en el marco de los convenios de salarios de 1962, establecieron que tanto exhibidores, como distribuidores nacionales y extranjeros no tendrían cargas impositivas en sus actividades, pero que dichas desgravaciones (calculadas en un $21 \%$ de lo recaudado en los espectáculos) debían destinarse a un fondo para cumplir con los ajustes salariales de los trabajadores de esta industria, incluidos los empleados locales de las empresas distribuidoras extranjeras. 4

Lo cierto es que, durante la primera mitad de la década de 1960, el fondo de desgravación para ajustes de salarios se descapitalizó, mientras que la concurrencia a los cines siguió descendiendo. Si bien este porcentaje de las ganancias seguía destinado al pago de salarios, las empresas comenzaban a tener dificultades para cumplir con los aumentos previstos en los convenios firmados con anterioridad. Por otra parte, los contratos por porcentaje de recaudación solo se firmaban entre los distribuidores y las

\footnotetext{
${ }^{2}$ República Oriental del Uruguay, Ley de Recursos para el presupuesto general de sueldos y gastos n. ${ }^{\circ}$ 13.319 del 28 de diciembre de 1964, https://www.impo.com.uy/bases/leyes/13319-1964.

${ }^{3}$ Alfredo Zitarrosa, «Crisis de los cines. Los peces crecen y se parecen», Marcha [Montevideo] Jun., 1965: 26.

${ }^{4}$ Idem. y Centro Cinematográfico del Uruguay, «Remitido. La Cinematografía Nacional se opone a ilegítimas presiones de Empresas Privadas Extranjeras que no aceptan actuar bajo una Ley Nacional», $L a$ Mañana, [Montevideo], Jun. 6, 1965: 5.
} 
empresas exhibidoras de mayor porte, siendo algunas de estas últimas distribuidoras también. En el caso de las salas pequeñas de exhibición, principalmente de carácter barrial o radicadas fuera de Montevideo, los contratos se establecían por costo fijo con las distribuidoras, quedando así fuera de lo comprendido en la ley presupuestal de 1964.5

En los meses previos a la aprobación de la lLey 13.319, y ante la situación de descenso de la concurrencia a espectáculos cinematográficos, las posibilidades de mantener los porcentajes de recaudación para aumentos salariales se habían visto comprometidos y la Motion Pictures había manifestado expresamente su falta de voluntad para renovar los marcos del convenio salarial existente. ${ }^{6}$ Sin embargo, lo dispuesto por ley en 1964 obligaba a los distribuidores a mantener el acuerdo señalado antes y, en ese marco, este conglomerado de distribuidoras extranjeras suprimió la distribución de estrenos norteamericanos en Uruguay, exigiendo que se derogara el artículo 32 de dicha ley. Esta situación provocó graves dificultades en numerosas salas de exhibición, en particular aquellas de menor porte que dependían de los estrenos de Hollywood para su supervivencia en el mercado.

A comienzos de junio de 1965, un grupo de exhibidores se escindió del Centro Cinematográfico del Uruguay -organización que hasta ese momento nucleaba al conjunto del sector-, conformando la Unión Cinematográfica de Exhibidores Independientes (UCEI) que resolvió en asamblea general:

\begin{abstract}
haciéndose presentes muchos exhibidores del Interior [y] tras analizar los diversos aspectos de la situación que opone en el Uruguay a los distribuidores estadounidenses y los exhibidores locales de las salas de estreno [...], propiciar ante los poderes públicos la derogación del cuestionado art. 32 de la Ley de Ordenamiento Financiero, siempre que las distribuidoras gestionen una autorización ante sus casas centrales en Nueva York por la cual se les permita arrendar su material de stock a los exhibidores independientes, mientras se tramita en Montevideo la derogación del artículo citado.7
\end{abstract}

La posición de esta nueva organización era consonante con lo expresado por la propia Motion Picture, la Unión de Empleados Cinematográficos y Glücksman Cinesa,

\footnotetext{
${ }^{5}$ Alfredo Zitarrosa, op. cit., Jun. 18, 1965: 26.

${ }^{6}$ Centro Cinematográfico del Uruguay, op. cit., Jun. 6, 1965: 5

${ }^{7}$ S.d.a., «Pro derogación del litigio», La Mañana, [Montevideo], Jun. 3, 1965: 9.
} 
que constituía uno de los principales circuitos de exhibición a nivel local. ${ }^{8}$ Entre los partidarios de no derogar el artículo estaban los otros tres grandes circuitos de exhibición CENSA, CCC y SAUDEC. 9 A través del Centro Cinematográfico del Uruguay respondieron a la posición de UCEI, así como a las declaraciones de la Motion Pictures a través de un remitido donde declaraban que ante

la respuesta dada por las siete empresas extranjeras al legislador nacional... a las vías y recursos puestos a su disposición por nuestro derecho positivo, prefiriendo decretar un boicot contra todas las empresas exhibidoras nacionales sin más fundamento que la fuerza del monopolio de hecho que ejercen sobre la mayor parte del material cinematográfico utilizado en el país, y sin otro fin que procurar ventajas pecuniarias adicionales respecto a las bases con que tradicionalmente han operado, idénticas al régimen resultante del art. 32 de la Ley 13.319.10

El conflicto mostró el posicionamiento de diversos grupos de interés en pugna, donde los sectores más débiles de la actividad económica de exhibición cinematográfica se organizaron en favor de lo que reclamaban los monopolios extranjeros, asumiendo la fragilidad de las iniciativas públicas y buscando proteger la supervivencia de su emprendimiento comercial.

Desde las páginas del semanario Marcha, el joven crítico de cine José Wainer manifestó una postura analítica frente a la globalidad del conflicto. Afirmaba que «fuentes responsables» señalaban que las acciones de las compañías CCC y SAUDEC estaban en manos de un solo empresario. Desde el punto de vista de Wainer, el conflicto no presentaba las clásicas contradicciones entre distribuidores y exhibidores, empresarios y trabajadores o Estado y empresarios. El panorama arrojaba luz sobre una serie de contradicciones y acciones de presión entre muy diversas partes interesadas, donde el bloqueo internacional en un mercado local dependiente, la ausencia de políticas de Estado para la industria cinematográfica, el temor a la quiebra o pérdida de empleo de diversos grupos del sector cinematográfico y la decidida agudización de la crisis económica general del país, pusieron de manifiesto que quienes controlaban la regulación y el consumo de la industria del cine en Uruguay de mediados de los sesenta eran monopolios ajenos a un

\footnotetext{
${ }^{8}$ José Wainer, «La crisis cinematográfica. Las patas de la sota», Marcha [Montevideo], Jul. 2, 1965: 27.

9 Ídem.

${ }^{10}$ Centro Cinematográfico del Uruguay, op. cit., Jun. 6, 1965: p. 5 .
} 
interés «nacional».11

Hacia fines de junio, el asesor jurídico de los distribuidores norteamericanos, Conrado Hughes, afirmaba en conferencia de prensa, en representación de todas las partes interesadas en la derogación del artículo 32:

\begin{abstract}
No nos venimos a quejar de los impuestos, o si nos quejamos, no nos alzamos contra ellos. El artículo 32 impone una quita a los ingresos de los distribuidores que no se destina al Fisco, sino que beneficia exclusivamente a la otra parte contratante en el negocio. Si bien esa detracción ya regía por un convenio privado, los distribuidores no están dispuestos a tolerar que eso se imponga por ley... porque significaría sentar un precedente perjudicial, tanto en nuestro medio como en los países vecinos. ${ }^{12}$
\end{abstract}

El conflicto desatado en aquel contexto, por un lado mostraba la fuerte dependencia de los circuitos comerciales de cine - sobre todo los pequeños- de los estrenos norteamericanos. A su vez, las medidas instituidas en esta materia se llevaron a cabo en un contexto de ingreso de la televisión a los hogares y disminución de la concurrencia del público. Por otra parte, esta crisis también ponía de manifiesto una serie de corporaciones, sindicatos y grupos de interés organizados en torno a esta industria, que hacían del cine un hecho social y económico indiscutible en el escenario local, fuertemente dependiente de la exhibición de productos norteamericanos, debido a la ausencia de una industria de carácter local. El conflicto se dirimió mediante la derogación del artículo en cuestión, dejando entrever que la supervivencia de los grupos implicados estaba sujeta a las posibilidades de exhibición de los estrenos de Hollywood.

Desde Marcha, acompañando la mirada «antimperialista» que había caracterizado al semanario en el ámbito local, José Wainer manifestaba una posición distinta a la señalada previamente por el conjunto de los actores. Wainer, observaba como, si bien durante 1965 se habían producido numerosos títulos uruguayos y existían industrias pujantes fuera del ámbito norteamericano tanto en la región como en otras latitudes, la crisis instalada por el boicot de la Motion Pictures no había estimulado el desarrollo de medidas locales que contrarrestaran los históricos hábitos de consumo cinematográfico

\footnotetext{
${ }^{11}$ José Wainer, op. cit, Jul. 2, 1965: 27.

12 Ídem.
} 
en la órbita comercial. Señalaba en su balance del año que

... la robusta tajada que los distribuidores independientes iban a recibir como franquicia derivada de la ausencia norteamericana, no cuajó, a fin de cuentas, en un sedimento capaz de subvertir los carriles de la rutina... La oferta fue rígida, unilateral, aplicada a sustituir una rutina por otra, igualmente estrecha y agobiadora, sin más horizonte que la saturación... Y ya que la oferta no se ha mostrado apta para desviar su signo e influir sobre la demanda, estaremos uncidos con más fuerza que nunca al material de Hollywood, que bien puede retornar a paso de conquistador..$^{13}$

Wainer se refería al conjunto de películas que se habían realizado aquel año en Uruguay, lamentando que la ausencia en la cartelera de los títulos internacionales más populares fruto del boicot, no hubiera estimulado una política pública más firme en relación a divulgar y estimular la producción nacional. Afirmaba en este sentido que:

... por definición, una crisis es un estado de transición, de manera que mientras se sufre es oportuno preguntar hacia dónde nos arrastra su corriente y si, pese a ella, no sería posible probar, entre tanto, los propios medios de desplazamiento. Dado que la actividad cinematográfica es entre nosotros un organismo con aparato digestivo voraz y organizado (un negocio de exhibición concentrado y sólido, plena ocupación entre los críticos, crecidos circuitos no comerciales), cuya hipertrofia se ha desarrollado casi en proporción directa a la atrofia de su aparato de reproducción (si así llamaramos al relegado cine nacional), no hay examen válido que pueda olvidar esa dicotomía, que en esta temporada se hizo especialmente nítida y tajante. No hay que forzar la percepción para advertir, ante todo, la masiva ausencia de Hollywood en las carteleras y, simultáneamente, la producción de un número de películas locales superior al de otros años. Por un lado las contradicciones internas que desgarran la explotación cinematográfica entre nosotros... alcanzaron un límite inusitado. Y si las fuerzas en conflicto han decretado una tregua para reagruparse y esperar una posible instancia por venir, desde mañana, por lo pronto cooperarán devotamente ad majorem gloria Hollywood. ${ }^{14}$

La oportunidad desechada de promoción del cine producido a nivel nacional o de la puesta en circulación de otras tendencias de producción cinematográfica, tras la crisis desatada en 1965 con el retiro de los estrenos norteamericanos en la cartelera, no tendría un mismo significado para el conjunto de actores locales que apostaban al desarrollo de una cinematografía alternativa de la que las salas de exhibición comercial resultaron claramente dependientes. Wainer desarrollaría una tarea sistemática desde las páginas de Marcha en defensa del cine documental, que denunciaba la situación acuciante de los países del Tercer Mundo. Durante la segunda mitad de la década de 1960, se constituyó como el principal vocero y difusor de los films producidos y difundidos por el

\footnotetext{
${ }^{13}$ José Wainer, «Cine en el Uruguay: una crisis bifronte», Marcha [Montevideo], Dic. 31, 1965: 15. 14 Ídem.
} 
Departamento de Cine de Marcha y su Cine Club entre 1968 y 1969 y por la Cinemateca del Tercer Mundo entre 1969 y 1973, afines a las corrientes del Nuevo Cine Latinoamericano. ${ }^{15}$

La segunda mitad de la década de 1960, pondría en escena a diversos actores locales cuya visión sobre el desarrollo del cine a nivel local encontraba fuertes divergencias entre sí. Los grupos organizados en torno a la exhibición comercial mostraron muy distintas reacciones frente a la presión de los monopolios extranjeros de distribución de títulos. Frente a este escenario, posiciones emergentes como la expresada por Wainer cuestionaban de forma global los conflictos de intereses de las diferentes partes y ponían de manifiesto la presencia de otros modos de producción que globalmente no eran tomados en cuenta en el ámbito de circulación comercial, como elementos de posible superación de aquella crisis.

\section{El cine uruguayo en debate}

Paralelamente, en los ámbitos cinéfilos y preocupados por la producción del cine local, también se expresaron posturas de carácter divergente. El ingreso de la televisión no solo tuvo su impacto en las formas de consumo de las películas y sus medios de circulación, también puso de manifiesto diversas posiciones en torno a la profesionalización de la actividad en el ámbito de la producción audiovisual por parte de la crítica local. A modo de ejemplo, a comienzos de 1967 el Cine Universitario del Uruguay relanzó su revista con el título Nuevo Fílm. ${ }^{16}$ En su editorial, se afirmaba que la publicación procuraba «... ocuparse en serio del cine... [y] servir al conocimiento y apreciación de este arte tratando de explicar sus distintos aspectos, y por esta vía lograr una elevación del nivel cultural».17 $\mathrm{Si}$ bien este mismo editorial dejaba libradas las interpretaciones o las valoraciones sobre diversos asuntos a cada autor, aclaraba que la revista en su conjunto buscaba tener una «finalidad didáctica por encima de cualquier

\footnotetext{
15 Ídem.

${ }^{16}$ Nuevo Film (nueva época), [Montevideo], 1967, 1, Cine Universitario del Uruguay.

${ }^{17}$ Idem., p. 14 .
} 
enfoque».18

Lo cierto es que el panorama sobre el cine uruguayo de fines de los sesenta brindado por Daniel Arijón no estuvo exento de valoraciones que posicionaron de manera decidida a los diversos grupos asociados a la producción cinematográfica. En su artículo «Cine uruguayo: una infancia permanente», el autor clasificaba a los cineastas de su generación entre los grupos de amateurs, los operadores de cámaras filmadoras, los funcionarios de departamentos de cine estatal, los free-lance que trabajaban tanto para Uruguay como para el exterior, los empresarios fundamentalmente asociados a la producción de films publicitarios y los que ensayaban en el campo del «largo-metraje argumentado». Señalaba que solo las tres últimas categorías estaban integradas por el «germen de la creación cinematográfica» y clasificaba este conjunto a su vez entre quienes lo realizaban por exclusivo placer y curiosidad por el conocimiento de los nuevos medios técnicos, los que tomaban la actividad como una forma de acceso a ciertos círculos sociales y «unos pocos [que] se acercan al cine para usarlo como un arma de denuncia social. Les interesa el planfleto, la documentación de la miseria, la creación de un escozor en la conciencia del raleado público al que exponen sus obras. Sus ideas serán discutibles o no, pero las sirven de la forma más mediocre posible».19

La posición de Arijón, fuertemente influida por una visión sobre la profesionalización del cine asociada a la adopción del modelo de producción y circulación de films propuesto por las grandes compañías monopólicas o por las cadenas de producción asociadas principalmente a la producción de imágenes para la televisión fue rebatida con dureza otra vez por Wainer desde las páginas de Marcha, quien devolvía una rotunda crítica a la publicación en su conjunto y señalaba sobre el artículo de Arijón que «después de trazar un panorama parcial y caprichoso, y desahogar algunos créditos pendientes contra críticos y colegas, termina reclamando al cine uruguayo autocrítica...». ${ }^{20}$ El crítico de Marcha, que para 1967 había estimulado desde las páginas del semanario el desarrollo de la producción de cine político y militante, que Arijón

\footnotetext{
${ }^{18}$ Nuevo Film (nueva época)..., p. 14

${ }^{19}$ Daniel Arijón, «Cine uruguayo : una infancia permanente», Nuevo Film [Montevideo], 1967, 1: 121.

${ }^{20}$ José Wainer, «Anestésico y encaje antiguo», Marcha [Montevideo], Jun. 30, 1967: 23.
} 
caracterizaba de forma casi paródica, señalaba con dureza que la solución para el cine nacional brindada por el artículo de Nuevo Film era la «producción de largometrajes en inglés para conquistar el mercado norteamericano y la implantación rigurosa de la libre empresa». ${ }^{21}$ En las cartas al lector del mismo semanario, un artículo anónimo criticaba con fuerza las consideraciones de Wainer sobre la revista Nuevo Film argumentando que una cultura cinematográfica «no se construye de la noche a la mañana» y «por algo hay que empezar, aunque sean "los cortos comerciales que consume la televisión vernácula", que permiten en algunos casos adquirir la técnica, el hábito del lenguaje cinematográfico, que luego se utilizarán en los largometrajes».22 Al igual que en el ámbito de los distribuidores y exhibidores de films, la polémica en el ámbito de la crítica de cine dejaba entrever también diferentes visiones acerca de cómo se gestaba el cine local y cuáles debían ser los canales de promoción para su producción.

La polémica entre Arijón y Wainer se produjo en el mismo momento en el que, por segunda vez, una película uruguaya era excluida del histórico Festival de Cine Documental y Experimental del SODRE, principal evento internacional de cine en Uruguay que se llevaba a cabo de forma oficial desde 1954. En su edición de 1960, el Festival había determinado que la película Como el Uruguay no hay de Ugo Ulive quedaría excluida del evento, apelando al artículo 3 del reglamento del festival, que indicaba la no admisión de films que «efectúen propaganda de hechos, sistemas o teorías políticas o religiosas, con fines proselitistas».23 En 1967, la película Elecciones de Mario Handler y Ugo Ulive, producida durante la campaña electoral del año anterior, en el marco de las actividades del Instituto de Cinematografía de la Universidad de la República, tampoco fue aceptada en dicho evento con el mismo argumento. Desde comienzos de 1967, Elecciones originó fuertes debates al interior de la institución universitaria, a raíz de cómo el documental expresaba el fenómeno de la democracia electoral en el país. ${ }^{24}$

\footnotetext{
${ }^{21}$ José Wainer, «Anestésico y encaje antiguo...

${ }^{22}$ A. S., «Nuevo Film», Marcha [Montevideo], Jul. 14, 1967: 3.

${ }^{23} \mathrm{M}$. Jacob, «Elecciones. Cuando los reglamentos atentan contra la creación artística», Hechos [Montevideo], May. 30,1967: 7.

${ }^{24}$ Con relación al debate interno que se produjo en la Universidad de la República a raíz de la película Elecciones, ver: Isabel Wschebor, «Cuando una película queda fuera del archivo. El debate en torno a la película Elecciones a medio siglo de su realización» (ponencia), en Primeras Jornadas sobre memoria,
} 
En mayo de 1967, el film fue presentado al VII Festival de Cine Documental y Experimental del SODRE donde no fue exhibido, quedando Handler y Ulive a la espera de una respuesta en relación con su incomunicada censura. Ante la presunción de que sería excluido del evento, los directores hicieron gestiones personales ante el organismo y mostraron el film al Ministro de Cultura Luis Hierro Gambardella quien manifestó que «desde el punto de vista de las libertades, nadie, creo yo, puede sentirse afectado por esta manifestación, una libertad que es un patrimonio de todos.»25 Pese a las opiniones del ministro, el film fue igualmente retirado del festival y, en ese marco, los directores organizaron una exhibición para la prensa especializada. José Wainer afirmaba en las páginas de Marcha que:

... el Festival terminó y el esperado estreno de Elecciones no se verificó. No será esta la oportunidad más propicia para enjuiciar el film, entonces. Bastaría decir, aunque no es bastante, que posee una calidad tan relevante, que se eleva sin esfuerzo a la más exigente jerarquía internacional... Bastaría decir que es una de las tentativas más serias y denodadas de estudio de nuestra realidad, y una mostración definitiva de la aptitud del cine como herramienta de autoconocimiento nacional. ${ }^{26}$

La censura del film también fue reprobada por la Asociación de Críticos Cinematográficos del Uruguay. ${ }^{27}$ La película fue finalmente estrenada a fines de junio de 1967, en el X Festival de Cine del Semanario Marcha. Para dicho año, el evento cinematográfico del semanario cambiaría de orientación con respecto a sus ediciones anteriores. Si en forma anual solía mostrarse el repertorio de películas mejor calificadas por sus críticos, aquel año mostró un vuelco hacia el cine latinoamericano y local, de carácter documental y político. En agosto del mismo año, Elecciones se anunciaba en la cartelera comercial del Cine Renacimiento de Walter Achugar, junto al Romance de Aniceto y Francisca del argentino Leonardo Fabio, apadrinada por el mismo productor. La publicidad en Marcha apuntaba a que se trataba de Elecciones (versión completa) ${ }^{28}$ y,

\footnotetext{
historia y presente de la izquierda en Uruguay, [Montevideo], Centro de Estudios Interdisciplinarios Uruguayos y Archivo General de Udelar, 2016. Con relación al debate sobre Elecciones ver también: Mariana Villaça «A crítica cinematográfica como campo de disputa política no Uruguai: a repercussão do documentário Elecciones (Mario Handler / Ugo Ulive, 1967)». Revista Antíteses, v. 10, p. 475-495, 2017.

${ }^{25}$ M. Jacob, op. cit., May. 30, 1967: 7.

${ }^{26}$ J. Wainer, «Festival del SODRE. Fin del juego», Marcha [Montevideo], May. 27, 1967: 25.

${ }^{27} \mathrm{ACCU}$, «Cine y libertad», Marcha [Montevideo], May. 19, 1965: 5 .

${ }^{28}$ «El romance de Aniceto y la Francisca y Elecciones (versión completa)», Marcha [Montevideo], Agos. 05, 1967: 25 .
} 
a fines de ese año, obtuvo el Premio de la Asociación de Críticos Cinematográficos del Uruguay.

A nivel local, las nuevas tendencias proclives al cine político y militante habían manifestado tiempo antes sus diferencias con la programación presentada por Cine Arte en el festival. Ya en 1965, José Wainer señalaba la progresiva rutinización del evento. ${ }^{29}$ Tras el regreso del joven cineasta Mario Handler de una beca en Europa, en 1965 afirmaban que «aunque la reglamentación del festival proscribe todo ejemplar de cine que contenga algún asomo de propaganda política o religiosa (fórmula sibilina si las hay), y con él, buena parte de la producción "documental y experimental” que proclama convocar, algunos títulos de cierto interés social se han podido deslizar entre el fárrago de films anodinos que vienen fatigando la paciencia de quienes acuden cotidianamente al estudio auditorio». 30

En 1967, la censura de Elecciones reforzó los puntos de vista del crítico de Marcha con respecto al festival del SODRE. Más allá de la censura local, Wainer planteaba consideraciones generales en relación con el programa. Afirmaba que estaba constituido por los mismos tipos de títulos, atestiguando el poco espacio que se brindaba a nivel público y privado a las tendencias crecientes del Nuevo Cine Latinoamericano. Si bien reivindicaba la interesante presencia de películas de animación, ${ }^{31}$ desde el punto de vista general, Wainer consideraba que

Poco importan el nombre del Festival: llegado a su séptima edición parece ocioso, ya, definir, el contenido de sus adjetivos (documental, experimental, internacional). Ni separadamente, ni sumados, o combinados, ni aún confrontados con la realidad de los films que se exhiben, admitirían, un deslinde rígido, y preciso... Ciertas cláusulas diacrónicas del reglamento, pongamos por caso, puestas para excluir países y géneros, según móviles no siempre académicos. $3^{2}$

A las posiciones emergentes de una nueva generación, volcada hacia la producción de un cine de denuncia, inspirado en las corrientes del Nuevo Cine Latinoamericano, se

\footnotetext{
${ }^{29}$ José Wainer, «Cine en el Uruguay: una crisis bifronte», Marcha [Montevideo], Dic. 31, 1965: 15.

${ }^{30}$ José Wainer y Mario Handler, «VI Festival del SODRE. Una pizca de interés social», Marcha [Montevideo], May. 14, 1965: 15.

${ }^{31}$ José Wainer, «Festival del Sodre Animación Über Alles», Marcha [Montevideo], May. 12, 1967: 27.

${ }^{32}$ José Wainer, «Festival del Sodre Parientes y amigos», Marcha [Montevideo], May. 05, 1967: 27.
} 
sumaba a mediados de la década de 1960 la mirada del cineasta Ferruccio Musitelli. Se trataba de uno de los pocos referentes a nivel local que contaba con una trayectoria de trabajo sostenida en medios de prensa internacional y a través de la cinematografía amateur y de autor en el ámbito local desde la década de 1950. A mediados de la década de 1960, Musitelli fue entrevistado por el diario Época, donde expresaba que a falta de un instituto especializado en la formación de cineastas en Uruguay, la capacitación requería de lecturas y «ver mucho cine».33 Sobre la posibilidades de producir cine en Uruguay, afirmaba que era una industria cara, con respecto a otras ramas, y que la inversión no ameritaba si se trataba de «hacer folletines intrascendentes».34 Por el contrario, creía

\begin{abstract}
necesario, para nuestro país, el desarrollo de un cine documental, altamente capacitado. Ya es tiempo que nos retratemos con todas nuestras virtudes y defectos, será una manera de salir del subdesarrollo... Las posibilidades están en relación con lo económico. Cuando podamos hacer películas que reflejen nuestra realidad, ello querrá decir que estaremos lejos de una crisis económica. Entonces no padeceremos la realidad de Hoy. Los cineastas italianos reflejaron la realidad del tiempo de guerra y en la post guerra. Nos queda la esperanza de rememorar mañana la crisis actual. 35
\end{abstract}

Este conjunto de posiciones sobre el cine nacional, mostraron una preocupación en torno al tema de su producción y su rol en el escenario de la cultura y la política. La relación entre el cine y el contexto político y social que vivía el país, parece haber sido un estímulo para interpelar los espacios institucionales existentes que, para ese entonces, se ocupaban del quehacer cinematográfico en el ámbito local. En ese marco, el debate entre los modelos clásicos de desarrollo del cine en Europa y Estados Unidos y el desarrollo de un cine que caracterizara desde perspectivas diversas la situación continental de América Latina constituyeron el núcleo de las polémicas de época que, vistas en su conjunto dan cuenta de un campo específico en el ámbito cultural hacia mediados de la década de 1960.

\title{
4. Identidades cinematográficas y conservación
}

Los debates en torno a qué cine mostrar o producir en Uruguay condicionaron a su vez, las decisiones en torno a qué películas guardar. El período que se inaugura en 1965

\footnotetext{
${ }^{33}$ «Estos son nuestros problemas. Musitelli: después alguien hará un film sobre este tema», Época [Montevideo], articulo conservado en el archivo privado de la familia Musitelli. Por su contenido, se trata de un artículo posterior a 1962 y anterior 1967.

${ }^{34}$ Ídem.

${ }^{35}$ «Estos son nuestros problemas. Musitelli: después...
} 
estuvo atravesado por diversos tipos de cambios en el ámbito institucional y de las relaciones internacionales, que impactaron en Cine Arte del SODRE y Cinemateca Uruguaya. Para ese entonces, se trataba de las principales instituciones especializadas en la colecta de archivos y colecciones de películas. En ambos espacios hubo renovación de autoridades y un impacto en las características de sus colecciones. Desde el punto de vista general, se trata de un período en el que Uruguay comienza a discutir aspectos específicos de la conservación y divulgación del cine nacional e internacional. En este sentido, nuevas posturas se hacían presentes en el debate, tomando distancia de ambos organismos a través de planteos que disentían de forma genérica con las prácticas y concepciones que habían guiado a los organismos público y privado desde la década anterior. Estas nuevas posturas con respecto al cine, encontrarán nuevamente entre sus animadores al crítico de cine en Marcha José Wainer, al joven cineasta Mario Handler y a Walter Achugar, joven uruguayo distribuidor de películas, interesado en la difusión de las nuevas corrientes del cine latinoamericano, vinculado con la denuncia política en relación con la realidad social y económica del continente. En los tres casos, se trató de personas claves en la fundación del Departamento de Cine de Marcha hacia fines de la década de 1960 y la creación de la Cinemateca del Tercer Mundo en 1969. Las polémicas que se iniciaron unos años antes pautaron decididamente la configuración de un nuevo grupo, que disintió con las posturas de las cinematecas existentes en Uruguay desde la década previa.

En 1965 Eugenio Hintz, histórico referente de Cine Club del Uruguay y de Cinemateca Uruguaya, asumió la dirección de Cine Arte del SODRE. Entre las propuestas señaladas por Hintz, se destacaba la puesta en práctica de proyecciones de cine nacional, apuntando además al rescate de «viejas películas uruguayas, a veces de importancia histórica, [que] han desaparecido por motivos diversos (como los incendios de Glücksmann y Uruguay al Día) o se echan a perder actualmente en manos de particulares sin medios aptos de conservación. "Se trata de un patrimonio nacional", dice Hintz sepultado entre papeles, "que no podemos resignarnos a perder"».36 Además de las proyecciones realizadas en las propias salas del SODRE, entre fines de $1965 \mathrm{y}$ comienzos de 1966 se organizaron las primeras retrospectivas de cine nacional en las salas del grupo

\footnotetext{
${ }^{36}$ Raúl Gadea, «Cine Arte Rescucita», Marcha [Montevideo] Abr. 24, 1966: 27.
} 
teatral La Máscara y en la Feria Nacional del Libro, valorizando de este modo las producciones uruguayas existentes hasta aquel momento. En este sentido, Hintz introducía en su propuesta la necesidad de crear «un archivo cinematográfico nacional». A un año de haber asumido, alertaba sobre «la impostergable necesidad de salvaguardar los restos de ese patrimonio nacional, muy diezmado por negligencia, desinterés y diversas catástrofes» y agregaba que «no se trata de rescatar un material más o menos curioso para regocijo de futuras generaciones, sino de crear un archivo histórico de cinematografía que permita a especialistas de distintas ramas (sociólogos, historiadores, cineístas, etc.), utilizarlos con fines de trabajo».37

Hacia la década de 1960, Hintz era una personalidad de referencia en el ámbito cinematográfico nacional. Desde su creación en 1950, integraba el Instituto de Cinematografía de la Universidad de la República dirigido por el Catedrático de Biología General y Experimental de la Facultad de Humanidades y Ciencias Rodolfo Tálice, 38 realizando una intensa labor de producción de cine científico e institucional y fue un referente en la conformación del cine-clubismo en el ámbito local desde los años cuarenta.

Si bien para ese entonces, el Uruguay ya contaba con diversas iniciativas estatales, asociadas al registro y acopio de una filmografía local, entre los que se destaca la creación del Departamento de Foto-Cinematografía del Ministerio de Instrucción Pública, la Sección Cinematografía y Fonografía Escolar del Consejo Nacional de Enseñanza Primaria y Normal o el ya mencionado Instituto de Cinematografía de la Universidad de la República, Hintz señalaba por primera vez un interés específico en la conformación de un archivo cinematográfico nacional, orientado a acopiar los muy diversos tipos de registros cinematográficos producidos en Uruguay hasta el momento. Señalaba que

... la tarea de recuperación del cine uruguayo aparece como sumamente dificultosa y no puede, por lo tanto, ser postergada. Los días perdidos suelen ser decisivos. Si algo queda aún de la

${ }^{37}$ Eugenio Hintz, «A la búsqueda del cine nacional perdido», Revista del SODRE [Montevideo] Nov., 1966: 55 .

${ }^{38}$ Por más información sobre la historia del Instituto de Cinematografía de la Universidad de la República véanse: Isabel Wschebor, «El cine y la ciencia reformista (1950-1960)» en Alicia Alted y Susana Sel (Compiladoras), Cine científico y educativo en España, Argentina y Uruguay (Madrid: UNED-Editorial Universitaria Ramón Areces, 2016); Isabel Wschebor, "Cine y Universidad en la crisis de la democracia (1960-1973)» en: Revista Encuentros Uruguayos (Montevideo: CEIU, Universidad de la República, 2013), v. VI, n. ${ }^{\circ} 1$, pp. $50-84$. 
cinematografía nacional -y hay razones para suponer que es así-, es indispensable descubrirlo y reunir las películas recuperadas con vistas al archivo cinematográfico nacional. Esto supone, desde luego, la salvaguarda de todos aquellos films uruguayos, sin excluir los de producción más reciente, teniendo en cuenta que las películas de hoy serán las primitivas del mañana. 39

En las consideraciones del director de Cine Arte en cuanto al inicio de la labor de acopio se ponían de relieve elementos como la identificación de productores pioneros del cine local, entre los que menciona a Félix Oliver o Lorenzo Adroher, de coleccionistas como Fernando Pereda, así como la necesidad de conocer otras fuentes e indicios de la producción de películas como documentos de época o testimonios de protagonistas y familiares. En alguna medida, Hintz reconocía en este universo un conjunto de elementos que permitirían dar forma a su proyecto de archivo cinematográfico nacional. Pese al señalamiento sobre la importancia de los registros fílmicos para muy diversos campos de estudio, el proyecto de Hintz se focalizó en la búsqueda y conservación de los títulos para una posible filmografía de las etapas primitivas del cine local. En ese marco, la institución oficial no puso de manifiesto la necesidad de conservar la filmografía producida en las décadas de 1950 y 1960.

Paralelamente, a comienzos de 1967 el Ministro de Instrucción Pública Luis Hierro Gambardella mantuvo una serie de reuniones con representantes de la Asociación de Críticos del Uruguay, Cinemateca Uruguaya, Cine Club, Cine Universitario y realizadores independientes, que buscaban analizar de qué manera el Estado podría ordenar su intervención en el mundo del cine. Estas reuniones permitieron debatir asuntos de orden urgente como el de las franquicias aduaneras, la subvención para la obtención de negativos y copias o la incorporación del depósito legal. Sin embargo, no se tradujeron en proyectos y medidas de carácter concreto. 40

Tras estos encuentros, en febrero de 1967, este conjunto de críticos y cineclubistas entregaron al Ministro un documento donde se informaba sobre la situación del cine uruguayo en aquel momento. La introducción del documento advertía que «el comentario

\footnotetext{
${ }^{39}$ Eugenio Hintz, op. cit., Nov. 1966: 58.

40 «Informe al ministre de Instrucción Pública», Boletín de la Asociación de Críticos del Uruguaya », [Montevideo], 1967. Centro de Documentación de la Cinemateca Uruguaya y Manuel Martínez Carril, «Informe al ministro», La Mañana, [Montevideo], Mar. 4, 1967.
} 
general es que [Uruguay]... que posee una cultura cinematográfica bastante desarrollada, no produce películas, conserva precariamente el material fílmico de valor histórico o artístico que tiene, y tampoco ha logrado establecer un sistema adecuado para la preparación de técnicos».41 Es interesante que la cuestión del «archivo fílmico», aparecía como una temática específica en la agenda de los colectivos vinculados al quehacer cinematográfico.

Lo cierto es que la sección del informe relativa a las temáticas de archivo, refería fundamentalmente a la situación del archivo de Cinemateca Uruguaya. Señalaban que «conserva un acervo fílmico sumamente importante desde el punto de vista de la historia y el arte cinematográfico». $4^{2}$ La mirada sobre el archivo que plantean en este informe está sujeta con claridad a la de preservación del cine internacional. Entre sus funciones principales, identificaban la de proveer de films a cine clubes e instituciones culturales para sus actividades.

En este período, la Cinemateca Uruguaya también estaba renovando sus cuadros de dirección. Tras los quebrantos de salud del histórico referente de la organización Walter Dassori, los jóvenes Manuel Martínez Carril y Luis Elbert habían asumido una serie de funciones que buscaban renovar las actividades del organismo. Entre las iniciativas impulsadas por Dassori desde 1965 que tuvieron continuidad en este período, se encontraba la formación de la Unión de Cinematecas de América Latina (UCAL), que nucleó a buena parte de la Cinematecas Latinoamericanas que se habían apartado de la FIAF en 1960 tras el conflicto de esta organización con Henry Langlois, referente de la Cinemateca Francesa, de especial influencia en el ámbito cinéfilo latinoamericano. Según el historiador Fabián Núñez, el devenir de UCAL mostró un vuelco hacia las corrientes del cine latinoamericano de denuncia social y política (Núñez, 2015). Se destaca a su vez que, durante el período transcurrido entre 1954 y 1978, Cinemateca Uruguaya acopió un centenar de películas producidas en Uruguay, entre las décadas de 1950 y 1960.43 Llama

\footnotetext{
${ }^{41}$ Ídem.

${ }^{42}$ Ídem.

${ }^{43}$ Lista de films en el informe de actividades de la Cinemateca Uruguaya, presentado en el Congreso de Lausanne, 1954. Archivos de la Federación Internacional de Archivos Fílmicos [Bruselas]. Catalogo presentado por la Cinemateca Uruguaya a la (C), 1978. Archivo de la Cinemateca de Toulouse, [Toulouse].
} 
la atención, sin embargo, que la inserción de Cinemateca Uruguaya en la UCAL y la problemática del cine conservado por la organización y producido en el país no fueron señalados de forma específica en el informe al Ministro Hierro Gambardella. Se privilegió en este caso el rol de la organización en lo referente a la preservación del cine internacional. Señalaban sus relaciones con la Unión Mundial de Museos, organización que para ese entonces estaba orientada por Henry Langlois, y aludían a los vínculos con la FIAF, aunque aún no habían retomado formalmente su solicitud de afiliación a dicha red internacional.

En ese marco, los primeros puntos de la agenda en torno a la temática de los archivos planteados a las autoridades gubernamentales por parte de Cinemateca Uruguaya, estaban orientados a mejorar la difusión cultural del cine internacional de calidad en el ámbito nacional. La necesidad de proveer de recursos para el sostén de un archivo fílmico en Uruguay tenía como principal interés, su «mantenimiento como moneda de intercambio con otras cinematecas para ampliar así el acervo uruguayo», agregando que en Uruguay existían copias difíciles de conseguir en otras partes, como $\mathrm{El}$ nacimiento de una nación (David Griffith, EE. UU., 1915).44 En el diálogo con los poderes públicos, el enriquecimiento de la cultura cinematográfica para esta comunidad de cinéfilos, seguía orientada por el acopio del cine internacional para fomentar sus circuitos culturales de exhibición.

En el marco del rol social y cultural que manifestaban cumplir, reclamaban la falta de subvenciones estatales para el desarrollo de tareas de copiados de films y adecuación de su conservación, así como la necesidad de restablecer las exoneraciones aduaneras para el ingreso de películas a Uruguay. Lo que identificaba al Uruguay en materia cinematográfica para este conjunto de organizaciones, era su conocimiento sobre los autores canónicos de los países europeos y norteamericanos. La ausencia de Cine Arte del SODRE en el informe, posicionaba el archivo de Cinemateca Uruguaya, como la institución de referencia en materia de conservación cinematográfica. Señalaban a su vez, la necesidad de implementar una figura de depósito legal y reclamaban la necesidad de que

\footnotetext{
${ }^{44}$ Informe al Ministro..., op. cit., 1967.
} 
la Cinemateca asumiera esta responsabilidad en el ámbito local. No se referían en este caso a las obras producidas en Uruguay, sino a la posibilidad de que las películas exhibidas en la cartelera comercial, fueran incorporadas al archivo de la Cinemateca Uruguaya tras la caducidad de los derechos de exhibición.

Es decir que, si bien se introduce la temática del depósito legal, como una modalidad de reglamentar y compatibilizar los derechos comerciales de exhibición, con las necesidades conservación patrimonial y difusión cultural, no se trataban de forma específica los aspectos asociados a la producción nacional. Aludían a este concepto como: «la obligatoriedad de depositar en la cinemateca las copias, después de su explotación comercial, que deben destruirse, al vencerse los plazos de exhibición. Hay que subrayar, aunque sea obvio, que el depósito legal vigente en varios países,... excluye todo propósito comercial, lo que comprende solo los derechos de conservación del material y su exhibición con fines culturales (cine clubes, centros de estudio, docencia, etc.)». 45

Desde un punto de vista genérico, es importante señalar que, a diferencia de Argentina o Brasil, hacia la década de 1960 el Uruguay mantenía una cadena de producción amateur y no existían canales regulados en materia de registro público de los films. A diferencia de otros bienes culturales como la literatura o la música, la producción cinematográfica en general no era objeto de regulación. El cine de denuncia política mantenía un carácter alternativo al documental o experimental producido en otros ámbitos por sus contenidos, objetivos y prácticas de exhibición, pero su cadena de producción era relativamente similar a la de la mayoría de las personas sensibilizadas por el desarrollo de una producción propia. A diferencia de otros debates asociados a los archivos del cine militante producido en Europa en la misma época (Roudé, 2017), donde el contenido de denuncia política posicionaba a esta producción en un ámbito alternativo al de las reglamentaciones exigidas por la institucionalidad de la época, en Uruguay, la ausencia de institucionalidad disolvía esta dicotomía. Por lo tanto, la producción y colecta de las películas estaba asociada en su mayor parte al interés de los coleccionistas, cineclubistas o animadores de los festivales locales de mayor repercusión pública.

\footnotetext{
${ }^{45}$ Informe al Ministro..., op. cit., 1967
} 
Lo cierto es que, a partir de mediados de los sesenta, el incremento de la producción de cine a nivel local, así como los requerimientos tecnológicos y de saberes asociados a la implantación de la televisión en el país, intensificaron el debate de las distintas posiciones sobre cuáles debían ser las perspectivas de producir cine, las estrategias de profesionalización del medio, así como el desarrollo de políticas públicas para el incentivo de la producción cinematográfica. Pese al incremento de la cinematografía amateur, los ámbitos de la crítica, la exhibición y la colecta clásicos en Uruguay, consideraban necesario el robustecimiento de la difusión de una cultura cinematográfica internacional, asociada a la exhibición de títulos en el ámbito cultural y el desarrollo de políticas orientadas a instituir espacios de formación en la materia. Desde Marcha, diversas voces polemizaron en relación con esta visión. Como vimos, José Wainer, Mario Handler o Walter Achugar fueron activos en el debate sobre estos asuntos, a partir de una posición orientada por el desarrollo de un cine documental local, vinculado con la visibilización y denuncia de las problemáticas acuciantes en América Latina y detractor del cine comercial proveniente de los Estados Unidos.

Carlos María Domínguez profundizó en los procesos de distanciamiento entre la comunidad cinéfila clásica y quienes se agruparon en torno al semanario Marcha, formaron allí un cine club y organizaron a posteriori la Cinemateca del Tercer Mundo. El autor enfatiza en los diversos conflictos vinculados con las alternativas de izquierda política que se expandieron en el período. Afirma que «las diferencias partidarias, en el país y en la izquierda, con sus vertientes soviética, cubana, china, anarquista, y su caótico borbollón de banderas, adhesiones y conflictos, revistieron el fin de un período cultural que en el mundo de la crítica cinematográfica uruguaya también marcó una ruptura» (Domínguez, 2013: 106).

Tal y como señala Domínguez, sin duda el histórico crítico de Marcha, Alfaro, que inició su carrera en el ámbito de la cinefilia clásica y posteriormente cobijó las posturas asociadas al Nuevo Cine Latinoamericano, promovió este proceso de transformación y albergó estas posiciones disidentes en aquel contexto. Con el anuncio de las transformaciones del Festival Cinematográfico de Marcha en 1967, afirmaba que «... todos hemos dormido alguna vez la siesta, de espaldas al país. La asociación de ideas 
que se me ocurre es: Momias. No la gran momia cultural que el país haya querido darse - si hay algo sano en todo esto es que el país ni se enteró-, sino el sueño de la momia propia, parasitaria, adosada al país en crisis y envuelta en la cinta aisladora de la cultura cinematográfica». Y agregaba luego que «si el sistema que lanza, promueve y distribuye el cine comercial del gigantesco aparato de las comunicaciones de masas, busca desinformar y adormecer a la gente, contestemos el reto, hagámonos oír, busquemos la manera de que lleguen al público los documentos sobre los hechos que los demás ocultan o desinforman. 46

De este modo, Alfaro abrazaba las posiciones de nuevos actores como José Wainer en el ámbito de la crítica, Mario Handler en el de la producción y Walter Achugar en el de la distribución y la exhibición, buscando jerarquizar una posición distinta en relación a lo que significaba la producción de cine en Uruguay. Estos colectivos manifestaron la necesidad de mostrar el cine que daba cuenta del advenimiento de la crisis tanto en Uruguay como en América Latina y polemizaron fuertemente con los hábitos de producción, exhibición y colecta que caracterizaban los ambientes de circulación cinematográfica no comercial ya consolidados. Es así que progresivamente fundaron espacios propios, cuya mayor expresión fue la creación de la Cinemateca del Tercer Mundo y su funcionamiento hasta el golpe de Estado en 1973, pese a sucesivos episodios de persecución y allanamiento durante todo el período.

Este conjunto de polémicas también explica por qué dichos films no fueron conservados en las cinematecas ya consolidadas para fines de la década de 1960 y mediados de la siguiente. El propio fundador de Cinemateca Uruguaya, Walter Dassori, vaticinó como «ese futuro milagro», que «las cinematecas preparan» y que «sus pacientes polillas de archivo no verán».47 El milagro de volver a ver lo que se produjo en el pasado. Esta «manía» de los cinetecarios a la que aludía Dassori, poco tiempo después de estas polémicas se vería condicionada por la supervivencia de estas organizaciones, tras la instalación del régimen dictatorial en 1973.

\footnotetext{
${ }^{46}$ Hugo Alfaro, Ver para querer (Montevideo: Biblioteca de Marcha), n. ${ }^{\circ}$ 5, 1970: 148.

${ }^{47}$ Walter Dassori, «Apuntes para una nota sobre Cinematecas en la revista Nuevo Film». Archivo Personal de Walter Dassori, Cinemateca Uruguaya, S.f.
} 
Como puede observarse entonces, los escenarios de producción, exhibición y conservación cinematográfica en el Uruguay de la década de 1960, se gestaron en un contexto principalmente asociado a conflictos de diversos grupos, cuya mirada sobre el rol social y cultural del cine se presentaba de forma diversa y a veces antagónica. Estas polémicas se produjeron al calor de una crisis económica, política y social en el país y en un contexto de transformación de los medios de comunicación. Así, las miradas sobre el cine conllevaron a posiciones sobre su rol como instrumento de denuncia de la crisis o sus posibilidades de desarrollo, en un contexto de expansión de otros medios de comunicación como la televisión. Estos sectores en pugna configuraron organizaciones de diverso tipo y que albergaron a su vez archivos cinematográficos de carácter diferente. Tras el advenimiento de la dictadura, la Cinemateca del Tercer Mundo fue disuelta de forma definitiva y su archivo quedó disperso. Los modelos de exhibición y conservación puestos en marcha por las comunidades cinéfilas clásicas permanecieron en el tiempo, con las dificultades asociadas a la libertad de expresión en dictadura. En ese sentido, las consideraciones actuales en torno al patrimonio cinematográfico local, sin duda están condicionadas por este contexto de crisis, que continuaron o discontinuaron ciertas expresiones del campo cinematográfico previo al período de la dictadura.

\section{Obras citadas}

Alvira, Pablo. «Lo viejo y lo nuevo. El documental uruguayo en tiempos turbulentos», en Uruguay se filma. Prácticas documentales (1920-199o), G. Torello (ed.), (Montevideo: Irrupciones, 2018), 171-194.

- «Cine y revolución en los años sesenta latinoamericanos. La violencia como tema en el cine de intervención política (Uruguay, Brasil y Argentina)», Historia y Espacio [Cali], Universidad del Valle, v. 12, n. ${ }^{\circ}$ 46, 2016: 157-186. Disponible en http://historiayespacio.univalle.edu.co/index.php/historiayespacio/article/view/ 4070

Amieva, Mariana, «El amateur "avanzado" como cine nacional: el caso del cine uruguayo en la década de 1950», Revista Imagofagia, [Buenos Aires], Asociación Argentina de Estudios sobre Cine y Audiovisual n. ${ }^{0}$ 16, 2017: 144-145. Disponible en: www.asaeca.org/imagofagia.

Domínguez, Carlos María, 24 Ilusiones por Segundo (Montevideo: Cinemateca Uruguaya, 2013).

Gauthier, Christophe. «Le cinéma : une mémoire culturelle», 1895. Revue de l'association française de recherche sur l'histoire du cinéma, [Paris], Association française de 
recherche sur l'Histoire du cinéma, n. ${ }^{0}$ 52, 2007: 9-26. Disponible en: https://journals.openedition.org/1895/1012.

- Qu'est-ce que le processus de patrimonialisation du cinéma? Conferencia realizada en la Alianza Francesa de Uruguay, en el marco de las actividades del Grupo de Estudios Audiovisuales de la Universidad de la República [Montevideo], Set. 15, 2018.

Izquierdo, Eugenia, Cine y preservación. Los archivos cinematográficos en la Argentina (Buenos Aires: Imago Mundi), 2021.

Lacruz, Cecilia. «La experiencia del semanario Marcha y el cine político en el Uruguay» en: Efectos de imagen. ¿Qué fue y qué es el cine militante?, Oscar Ariel Cabezas Villalobos y Elixabete Ansa Goicoechea (eds.), (Santiago de Chile: LOMUniversidad Metropolitana de Ciencias de la Educación, 2014), 23-39.

- $\quad$ Modernidad y política en el cortometraje documental uruguayo: estrategias cinematográficas de una escena inaugural», Revista Imagofagia [Buenos Aires], Asociación Argentina de Estudios sobre Cine y Audiovisual. Disponible en: www.asaeca.org/imagofagia, n. ${ }^{\circ}$ 12, 2015.

- $\quad$ «Rostros, voces, miradas: notas sobre el pueblo en el cine documental uruguayo de los años sesenta» en: Uruguay se filma. Prácticas documentales (1920-199o), Georgina Torello (ed.) (Montevideo: Irrupciones Grupo Editor, 2018), 141-170.

- «La comezón por el intercambio» en: Las rupturas del 68 en el cine de América Latina, Mariano Mestman (coord.), (Buenos Aires: Akal, 2016), pp. 311-351.

«1965: contra el desconocimiento mutuo en el Cono Sur», Revista Cine Documental [Buenos Aires], n. ${ }^{\circ}$ 18, 2018: 37-61.

Núñez, Fabian. «Notas para um estudo sobre a Unión de Cinematecas de América Latina», Significação, v. 42, n. ${ }^{\circ}$ 44, 2015: 63-81.

- $\quad$ Núñez (Fabian), « Notas para um estudo sobre a Unión de Cinematecas de América Latina » dans Significaçao, v. 42, n. ${ }^{\circ} 44,2015$, pp. 63-81.

- F. Nuñez «Unión de Cinematecas de América Latina. Reflexòes sobre o seu processo histórico (1965-1984)» en Revista Encuentros Latinoamericanos, v. IV, n. ${ }^{0}$ 2, julio/diciembre 2020, pp. 163-183.

Roudé, Cathérine, Le cinéma militant à l'heure des collectifs (Rennes: Presses Universitaires de Rennes, 2017).

Silveira, Germán, Cultura y cinefilia. Historia de público de Cinemateca Uruguaya, (Montevideo: Cinemateca Uruguaya, 2019).

Villaça, Mariana. «A crítica cinematográfica como campo de disputa política no Uruguai: a repercussão do documentário Elecciones (Mario Handler / Ugo Ulive, 1967)». Revista Antíteses, v. 10, pp. 475-495, 2017.

Tadeo Fuica, Beatriz. «¿Qué mostrar? ¿Cómo cuidar? Análisis de colaboraciones entre incipientes cinematecas para enfrentar dilemas comunes durante los años cincuenta», Revista Encuentros Latinoamericanos [Montevideo], v. IV, n. ${ }^{\circ}$ 2, julio/diciembre 2020: 52-68. 
- Uruguayan cinema, 1960-2010. Text, materiality, archive (Nueva York: Tamesis, 2017) 